\title{
Salinity Transport in the Florida Straits
}

\author{
ZOLTAN B. SZUTS \\ Max Planck Institute for Meteorology, Hamburg, Germany \\ CHRIS MEINEN \\ Atlantic Oceanographic and Meteorological Laboratory, NOAA, Miami, Florida
}

(Manuscript received 5 July 2012, in final form 20 December 2012)

\begin{abstract}
A submarine cable across the Florida Straits yields a time series of volume and temperature transports using previously determined calibrations, and here a calibration is defined for salinity transport using data not yet compared to the cable. Since 2001, 32 transects were collected with conductivity-temperature-depth (CTDs) sensors and lowered acoustic Doppler current profilers (LADCPs). Calibrations for volume and temperature transports using CTD/LADCP data are consistent with previous studies. A salinity calibration is obtained by regressing salinity transport against volume transport, where salinity transport is calculated relative to the basin-averaged salinity at $26^{\circ} \mathrm{N}\left(S_{\text {ref }}=35.156 \mathrm{psu}\right)$. On average, the transect-derived salinity transport is $33.0 \mathrm{~Sv}$ psu $\left(1 \mathrm{~Sv} \equiv 10^{6} \mathrm{~m}^{3} \mathrm{~s}^{-1}\right)$, has a standard deviation of $2.8 \mathrm{~Sv}$ psu, and has a 90 th percentile range of 29.1-37.4 Sv psu. The cable-derived salinity transport has a root-mean-square error of $2.2 \mathrm{~Sv}$ psu compared to the CTD/LADCP transects. Inherent spatial fluctuations and their covariability in the Florida Straits are responsible for noise in the calibrations and for slight increases in accuracy from salinity to temperature to volume calibrations. Salinity fluctuations are strongest in middepth waters of intermediate salinity, where velocity is neither particularily fast nor variable. In contrast, temperature is highly stratified and warm nearsurface waters coincide with fast and variable velocities. Temperature additionally exhibits seasonality near the surface, whereas no robust seasonality is found for salinity or velocity. Temperature and salinity transports are largely driven by volume transport, which in turn, because of a large average electrical conductivity, is closely related to the conductivity-weighted velocity that generates the cable-measured voltage.
\end{abstract}

\section{Introduction}

Ocean circulation is driven in part by inhomogeneous evaporation and precipitation at the surface, which oceanic freshwater fluxes act to balance on a global scale. Perturbations in the mean freshwater flux, such as "Great Salinity Anomalies" in the subpolar North Atlantic (Belkin et al. 1998), can influence the buoyancy-driven circulation (Curry et al. 1998) and are a primary source for long periods of fluctuations of overturning strength (Biastoch et al. 2009; Beal et al. 2011). Modeling studies (e.g., Cimatoribus et al. 2012) suggest that salt import into the South Atlantic determines whether the Atlantic meridional overturning circulation (AMOC) has two stable states or not. While the surface branch of AMOC

Corresponding author address: Zoltan B. Szuts, Max Planck Institute for Meteorology, Bundesstrasse 53, 20146 Hamburg, Germany.

E-mail: zoltan.szuts@zmaw.de transits the equatorial zone, salt balances in the uppersubtropical ocean may also modify these waters as they transit to regions of deep convection.

Basinwide fluxes have historically been obtained from hydrographic transects. Transects across the Atlantic at $26^{\circ} \mathrm{N}$ show a net northward salt flux of $19 \pm 10 \mathrm{~Sv}$ psu $\left(1 \mathrm{~Sv} \equiv 10^{6} \mathrm{~m}^{3} \mathrm{~s}^{-1}\right)$ (Lavín et al. 2003), but its temporal variability is poorly understood. The $26^{\circ} \mathrm{N}$ AMOC array ${ }^{1}$ monitors the overturning circulation at this latitude and enables the calculation of time series of volume flux

\footnotetext{
${ }^{1}$ This array is a collaboration between the Rapid Climate Change (RAPID)-MOC project in the United Kingdom, funded by the Natural Enviroment Research Council (NERC); the MOC Heat Flux Array (MOCHA) project in the United States, funded by the National Science Foundation (NSF); and the Western Boundary Time Series (WBTS) project in the United States, funded by the National Oceanic and Atmospheric Administration (NOAA).
} 
(Cunningham et al. 2007) and heat flux (Johns et al. 2011), which has improved our understanding of the mean as well as the temporal variability. Just as for the volume and heat flux calculations, determining the basinwide freshwater transport will require a careful consideration of the flow in the basin interior, in the wind-driven Ekman layer, and in the Florida Straits. This paper focuses on estimating the contribution in the straits from the Florida Current.

Salinity transport is calculated from calibration transects with hydrographic and velocity measurements (section 2). Statistical correlation with the volume transport is used to relate the directly measured salinity transports to volume transports from a submarine cable that crosses the straits (section 3). This allows the calculation of a time series of salinity transport, including its vertical structure (section 4). Although this is a general method for interpreting cable measurements, its accuracy depends on the inherent covariability of velocity and salinity fields (section 5). Since the Florida Current is the major source of northward salt transport, the accuracy of this calculation is important for basinscale salt budgets (section 6).

\section{Data}

The Florida Current has been measured for many years in the Florida Straits using a variety of observing systems, including ship sections, moorings, and submarine cables. Retired telecommunications cables across the straits (e.g., Larsen and Sanford 1985) measure the electric field induced by the motion of salt ions through the Earth's magnetic field. The cable voltage is calibrated into a continuous time series estimate of volume transport using concurrent ship-based velocity observations (Molinari et al. 1985; Meinen et al. 2010). Since 2001, calibration sections have also been collected using conductivity-temperature-depth (CTD) instruments and lowered acoustic Doppler current profilers (LADCPs) about 3-4 times per year, yielding simultaneous measurements of temperature, salinity, and velocity. The CTD/LADCP data are presented here for the first time.

Each transect occupies nine stations across the Florida Straits at $27^{\circ} \mathrm{N}$ (Fig. 1), the same locations occupied by other calibration efforts since the 1980s (e.g., Spain and Sanford 1987). We use 32 CTD/LADCP transects collected through mid-2010. Each transect takes 12-14 h to occupy. The CTD data have a vertical resolution of $1 \mathrm{~m}$, while the LADCP velocities have a vertical resolution of $10 \mathrm{~m}$. Temperature data are presented here as potential temperature. Northward LADCP velocities are detided by removing a barotropic velocity calculated with tidal constituents from Mayer et al. (1984), following Meinen et al. (2010).

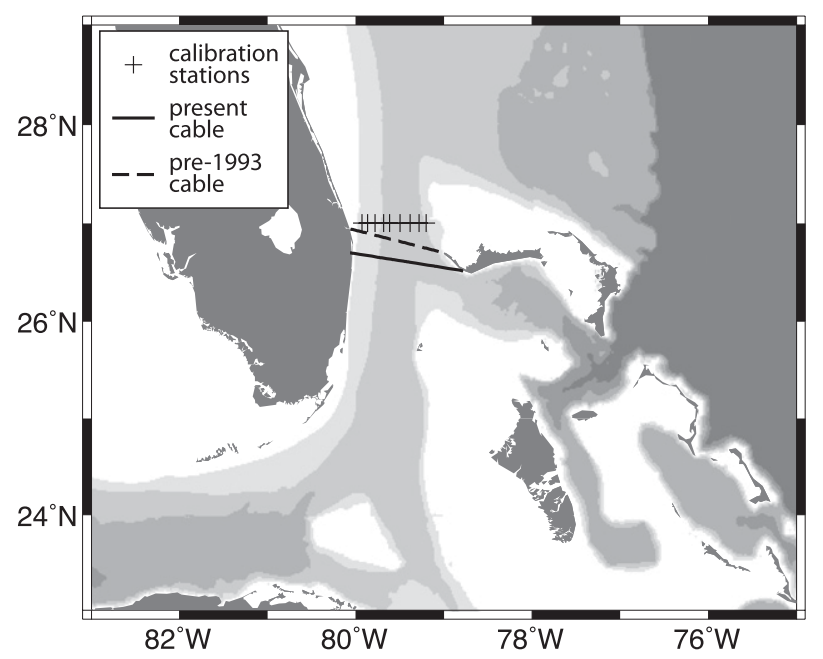

FIG. 1. Location of the calibration stations, the cable used for transport measurements from 1982 to 1993 , and the cable presently used for transport measurements.

Calibration data have previously been collected using free-falling velocity profilers. As part of the Subtropical Atlantic Climate Studies (STACs) program in the early 1980s, the Pegasus profiler (Spain et al. 1981) collected 84 transects of absolute velocity measured by acoustic bottom tracking of the free-falling instrument (Molinari et al. 1985). These transects allowed for initial and subsequent cable calibration studies (Molinari et al. 1985; Larsen and Sanford 1985; Shoosmith et al. 2005; Johns et al. 2011). Cable stability has been operationally verified since 1991, with 197 transects (65 since 2001) using dropsondes that measure vertically averaged velocity (Meinen et al. 2010). The dropsondes, constructed by NOAA's Atlantic Oceanographic and Meteorological Laboratory (AOML), are deployed by ship and function by falling to the seafloor, releasing a ballast weight, and ascending to the surface. Because of uniform fall and ascent rates, GPS surface tracking before and after deployment enables the vertically averaged horizontal velocity to be calculated. Dropsonde transects take $<8 \mathrm{~h}$ and are collected $8-10$ times per year by NOAA/AOML using small boats, to allow monitoring and correction of electrode voltage offsets in the raw cable measurement.

A cable has been used between Florida and the Bahamas to monitor the Florida Current transport nearly continuously since 1982 . The present cable has been in use since 1993. Details of its history are given by Meinen et al. (2010), while the theory behind its operation can be found in Sanford (1971), Larsen (1992), and Szuts (2012). The operational scale factor to give volume transport from the corrected cable voltage $\left(24.42 \mathrm{~Sv} \mathrm{~V}^{-1}\right)$ was calculated by Larsen (1992) on a nearby cable. Since 1993, 179 dropsonde calibration transects used with the 
present cable confirm that the original scale factor calibration remains highly accurate. Throughout the rest of the article, transports derived from the cable voltages will be referred to as cable transports.

\section{a. Calculating transports}

Prior to calculating transports, the CTD/LADCP profiles of temperature, salinity, and velocity are linearly interpolated onto a uniform grid. The grid has spacings of $1 \mathrm{dbar}$ in the vertical and $1 \mathrm{~km}$ in the horizontal, with bathymetric data from high-resolution echo sounder data collected by Larsen (1992). In addition to the simple linear interpolation, to complete the full cross section of the Florida Straits two areas must be considered. The first area is close to the bottom and "bottom triangles" between station pairs at different water depths. The bottom-most measured values are carried downward to the seafloor, and the bottom triangles are filled by linear interpolation. The second area is between the coasts and the outer-most stations. These outer triangles are filled by repeating the outermost station values horizontally to the seafloor and coast. No smoothing is performed in the gridding process.

With velocity, temperature, and salinity now on uniform grids over the entire straits, transports of volume, temperature, and salinity are straightforward areal integrals that are numerically implemented with summation over all valid gridpoints $j$ multiplied by their corresponding area $A_{j}$ : volume transport is the summation of northward velocity $T^{\mathrm{vol}}=\sum A_{i} v_{j}$, for velocity $v$; temperature transport is the summation of $T^{\mathrm{temp}}=\sum A_{j} v_{j}\left(\theta_{j}-\theta_{\text {ref }}\right) \sigma_{\theta} C_{p}$, for potential temperature $\theta$, potential density $\sigma_{\theta}$, heat capacity $C_{p}$, a reference potential temperature $\theta_{\text {ref }}$; and salinity transport is $T^{\mathrm{sal}}=\sum A_{j} v_{j}\left(S-S_{\text {ref }}\right)$, for a given reference salinity $S_{\text {ref. The reference quantities }} \theta_{\text {ref }}$ and $S_{\text {ref }}$ used here are basinwide averages $\left(5.33^{\circ} \mathrm{C}\right.$ and $35.156 \mathrm{psu}$ ), chosen to be suitable for flux calculations across the entire Atlantic at $26^{\circ} \mathrm{N}$. Temperature transport is calculated using a uniform value for $\sigma_{\theta} C_{p}$ of $4.1 \times 10^{6} \mathrm{~J}^{\circ} \mathrm{C}^{-1} \mathrm{~m}^{-3}$ following Johns et al. (2011).

Recent cable calibration efforts are based on dropsonde measurements of vertically averaged velocities (Meinen et al. 2010), which leads to a 1D integral across the straits. In contrast, the CTD/LADCP profiles need to be integrated vertically in addition to horizontally. Our use of an areal integral is similar to the calculations done by Shoosmith et al. (2005).

\section{b. Seasonal cycles}

It is well established that there are yearly cycles in the Florida Straits (Larsen 1992). This is most obvious in temperature (Shoosmith et al. 2005; Johns et al. 2011), but there is also a small seasonal cycle in velocity
(Baringer and Larsen 2001). Because there is variance in volume transport at all periods (weekly to interannual), however, the small seasonal cycle in volume transport requires many years of continuous observations to estimate accurately (Meinen et al. 2010).

The CTD/LADCP dataset is only marginally suitable for calculating seasonality due to the limited number of transects and the lack of an even distribution throughout the year. The only robust seasonal cycle is in temperature: it occurs in the upper $100 \mathrm{~m}$, has an amplitude of $2^{\circ}-3^{\circ} \mathrm{C}$, is maximum in August-September, explains $90 \%$ of the variance in the upper $50 \mathrm{~m}$, and reflects seasonal heating at the surface. Weighting the average temperature by velocity, called the transport-weighted temperature, yields a seasonal cycle that closely agrees with that found by Johns et al. (2011) using the historical Pegasus profiles. It is not surprising to find no seasonal cycle in velocity, given the small sample size. For salinity, we would expect any potential seasonality to occur in tandem with temperature and thus be largest in the upper $100 \mathrm{~m}$. The lack of a near-surface seasonality in salinity, however, implies that air-sea fluxes upstream of the Florida Straits have either little seasonal cycle or limited coherence by the time they reach the straits.

Based on the above-mentioned results, we make no correction for seasonality to the transect velocity or salinity or to the cable measurements. The seasonality in temperature is clear, however, and must be included. We do so by calculating a seasonal temperature anomaly for each transect that is obtained as follows: 1) calculate the annual harmonic from the 32 occupations at every depth in each station, only accepting statistically significant annual signals above $150 \mathrm{~m}$; 2) reconstruct the magnitude of the annual harmonic for each CTD profile based on its date of occupation; 3) vertically smooth each of the reconstructed profiles following Curry et al. (2011); and 4) grid the nine profiles of each transect using the method described in section 2a. The resulting gridded seasonal temperature anomalies can be subtracted from the gridded temperatures to remove the seasonal cycle.

\section{Calibrating the cable with CTD/LADCP transects}

The calibration of the cable for salinity transport consists of defining a linear relationship between the directly measured transports and the submarine cable transports. Ideally, such a relationship should be robust and usable without biases in a predictive fashion.

We calculate best-fit lines with principal component analysis (PCA). Unlike least squares, PCA assumes that there are errors in both the independent and dependent 
variables. Geometrically, the shortest distance to the best-fit line is minimized, in contrast to the vertical distance for least squares. By taking errors in both variables into consideration, the PCA fit is less sensitive to outlying points (Emery and Thomson 1998). Similar statistical considerations were used for previous cable calibrations: Larsen (1992) used a robust least squares method, while Shoosmith et al. (2005) used a model 2 geometric mean regression. Of the many available methods, we chose PCA for simplicity. Because linear least squares maximizes correlation by definition, any alternative fitting method (weighted least squares, model 2 regression, Gauss-Markov fitting) trades off correlation for an alternative property deemed important (Wunsch 2006; Szuts et al. 2011). Specifically, the PCA fit maximizes the variance explained for the two quantities used in the analysis. As our goal is to estimate only one of the quantities, we calculate its generalized correlation coefficients $R$, defined as the square root of the variance explained divided by its total variance. A specific comparison between PCA and least squares is provided below in section 3a.

Because PCA lacks closed formulas for calculating confidence limits, we determine them heuristically through bootstrapping. A random sample of 32 points is withdrawn with replacement from the available dataset of 32 transects, and a PCA fit is calculated on the random sample. This process is repeated 500 times, giving 500 samples of PCA fit, root-mean-square (rms) error, $R$, and sample standard deviation. The median parameters from the 500 repetitions are taken as the statistics of the best-fit line, and their $95 \%$ confidence limits are given by the $2.5 \%$ and $97.5 \%$ percentiles.

The limiting factor in the accuracy of our calibration is the small number of CTD/LADCP transects available $(N=32)$. The transects did not sample many transport extrema, and so the few extrema measured have a large influence on the fit regardless of whether least squares or PCA is used. The given distribution of the calibration data is accurately reflected by the use of bootstrapping to calculate confidence intervals.

When comparing or applying the calibration fits to other datasets (cable voltage, other calibration transects), mismatches between sample averages may cause biases. We expect that the linear relation between volume and salinity transports is independent of slight differences of the sample averages. The recommended cable calibrations are presented (in Table 2) by removing the average quantities first, in the form of $y-\bar{y}=m(x-\bar{x})$.

Before calculating a calibration for salinity transport, first we demonstrate that the CTD/LADCP dataset replicates previously calculated calibrations of volume

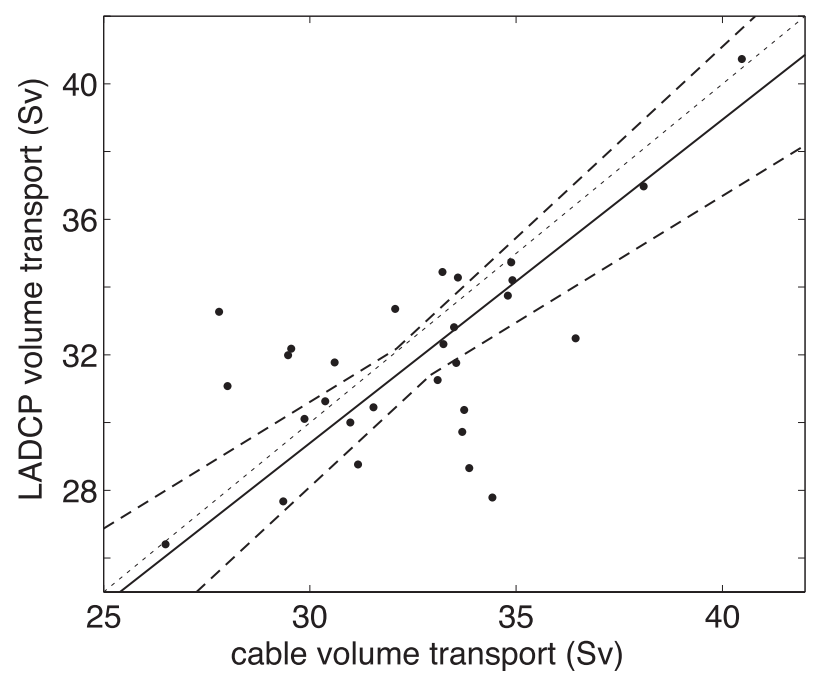

FIG. 2. Scatterplot between LADCP-derived volume transport and cable-derived volume transport (dots). Best-fit line (solid) is calculated using PCA with $95 \%$ confidence limits from a bootstrap analysis (see text, statistics given in Table 1), and a 1:1 slope is plotted (dotted) for reference. Confidence limits of the slope (dashed) are graphically shown offset relative to the sample means of the $x$ and $y$ variables by the ellipse formed by the respective standard errors of the mean.

and temperature transports. Following Shoosmith et al. (2005) and Johns et al. (2011), we use the calibration transects to first define a linear relation between volume transport and temperature or salinity transport that then can be applied to the cable transport time series.

\section{a. Volume transport}

The volume calibration calculated from the LADCP transects (Fig. 2) is consistent with prior calibrations from Pegasus transects (Larsen 1992; Shoosmith et al. 2005). The slope between LADCP transports and concurrent cable transports is close to $1[m=0.96(0.75$, 1.13), $95 \%$ confidence limits from boostrap analysis] and the $y$ intercept is indistinguishable from zero $\left[y_{0}=0.7\right.$ $(-5.6,7.7)]$, yielding an rms difference of $2.4 \mathrm{~Sv}$. Transects collected with dropsondes (65 since 2001) further confirm that previous calibrations remain valid, with $\mathrm{rms}$ errors of 1.6 Sv between 2001 and 2004 and of $1.4 \mathrm{~Sv}$ after 2004, when the recording system was modified to reduce electrical noise. As the dropsonde data are used to confirm operational accuracy, subsequent error analysis will consider the accuracy of cable-derived transport to be $1.6 \mathrm{~Sv}$ over the period 2001-10.

The LADCP transects have not previously been used to define a volume transport calibration, so their statistical agreement with the operational cable calibration given by the 1:1 line (Fig. 2) is reassuring. Though not statistically significant, the fact that the LADCP calibration 
lies lower than the 1:1 line is consistent with the fact that LADCP volume transports are $0.1 \mathrm{~Sv}$ lower on average than the mean cable-derived transport since 2001. The correlation coefficient given by calibrations using historical data [Larsen (1992), $R=0.97$; Shoosmith et al. (2005), $R=$ 0.96 from Pegasus profiles collected between 1982 and $1984]$ is higher than those using recent measurements ( $R=0.81$ from dropsondes since 2001, $R=0.54$ from LADCP transects). Although the cable measurement system has changed slightly since its original calibrationby using a cable farther south since 1993 and by removing magnetotelluric noise by low-pass filtering (since 2000) instead of by magnetic transfer functions (Larsen 1992) we suspect that the LADCP velocities are noisier than previous calibration instruments. The Pegasus measured velocity at each depth using Doppler shifting of signals from seafloor transponders, while dropsondes rely on GPS position fixes at the surface. In contrast, LADCPs measure Doppler shifting from particulate matter in the water and require correction for motion of the instrument package and the support vessel. Another likely source of noise is that the longer time required for a CTD/LADCP transect can introduce errors due to the asynopticity of the section data.

The calibration for volume calibration can also be used to assess the use of PCA regressions. In comparison to the PCA fit, linear least squares with the same bootstrapping approach for confidence limits yields a fit of $m=0.62(0.44,0.73), y_{0}=11.7(7.8,17.5)$, and $R=0.65$ $(0.50,0.73)$. The correlation is indeed larger than for the PCA, but not within statistical significance. More importantly, physical interpretation is harder: the fit does not agree with a 1:1 line and the large $y$ intercept is physically unmeaningful in terms of the theory of motional induction. The same problems arise in the results of a linear regression using the dropsonde calibrations since 2001. Compare this with the much smaller $y$ intercept found by Larsen (1992) using a robust implementation of least squares, $0.9 \pm 0.8 \mathrm{~Sv}$. As a further example, consider the single measurement of the largest LADCP volume transport (40 Sv), which is well within the distribution sampled by Pegasus and dropsonde transects (Larsen 1992) and lies close to the 1:1 line. The influence of this data point on a least squares regression can be quantified by Cook's distance (Cook 1979), a summation of squared differences between a fit with and without the point in question. This point's Cook's distance is an order of magnitude larger than the other points, indicating its large influence on the fit because of its extreme $x$ value, not because of its distance from the regression itself. We prefer to avoid linear regression because of its physically unmeaningful results and this example of its high sensitivity to outlying points.

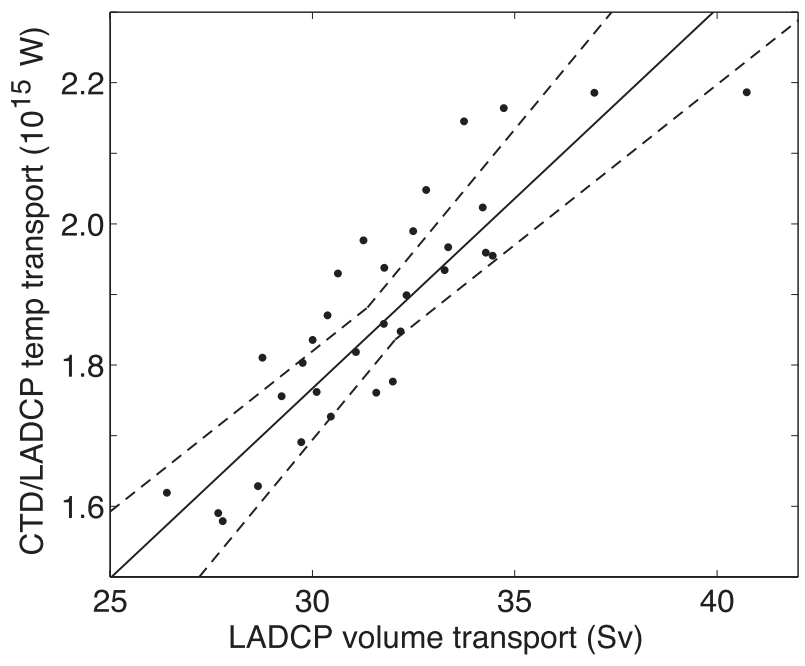

FIG. 3. Scatterplot between CTD/LADCP temperature transport relative to $\theta_{\text {ref }}=5.33^{\circ} \mathrm{C}$ and LADCP volume transport (dots). Best-fit line (solid) is calculated using PCA with $95 \%$ confidence intervals from a bootstrap analysis (see text, statistics given in Table 1). Confidence limits of the slope (dashed) are graphically shown offset relative to the sample means of the $x$ and $y$ variables by the ellipse formed by the respective standard errors of the mean.

\section{b. Temperature transport}

The relation between CTD/LADCP temperature transport and LADCP volume transport is calculated with the same statistical approach used above. To account for seasonality in temperature, the seasonal temperature anomaly is subtracted from the CTD-measured temperature before calculating the temperature transport. The best-fit line is found based on the de-seasoned temperature transports, but the correlation coefficients and variances are calculated relative to the full signal including the seasonal cycle. The resulting statistics are a combination of coherence between volume and temperature transports as well as the predictability of the seasonal cycle of temperature. In practice, the seasonal cycle of temperature transport is easily added to the cable estimate by making use of the date of measurement.

The choice of reference temperature affects the quality of the fits and their scientific interpretation. To show the temperature transport that contributes to basinwide heat flux, we use the basin-averaged temperature $\left(\theta=5.33^{\circ} \mathrm{C}\right.$; Hall and Bryden 1982) as a reference. Using a common alternative of $\theta_{\text {ref }}=0^{\circ} \mathrm{C}$ would increase the temperature transport, but the increase is less physically meaningful because it is partially compensated by the southward transport across the basin of water warmer than $0^{\circ}$. Nevertheless, for certain heat flux calculations this alternative reference may be preferred for ease of calculation.

Temperature transport relative to $\theta_{\text {ref }}=5.33^{\circ} \mathrm{C}$ (Fig. 3) is highly correlated $(R=0.93)$ with volume transport, 
TABLE 1. Summary of regressions against volume transport, calculated against (top) cable-derived transports or (bottom) from CTD/ LADCP calibration transects. Linear fits are calculated with PCA, which is applied in a bootstrapping approach to obtain median values and their $95 \%$ confidence intervals (see text). Fits are of the form $y=m x+y_{0}$, where $x$ is volume transport, $y$ is the variable in the first column, $m$ is the slope, and $y_{0}$ is the $y$ intercept. Correlation coefficients $R$ and rms residual errors are also given, in addition to the sample size used $N$.

\begin{tabular}{|c|c|c|c|c|c|}
\hline Cable transport & $m$ & $y_{0}$ & $R$ & rms error & $N$ \\
\hline Volume transport, LADCP & $0.96 \mathrm{~Sv} \mathrm{~Sv}^{-1}(0.75,1.13)$ & $0.7 \mathrm{~Sv}(-5.6,7.7)$ & $0.54(-, 0.87)$ & 2.4 Sv $(1.7,3.0)$ & 29 \\
\hline Calibration transport & $m$ & $y_{0}$ & $R$ & rms error & $N$ \\
\hline $\begin{array}{l}\text { Temperature transport, } \\
T_{\text {ref }}=5.33^{\circ} \mathrm{C}\end{array}$ & $0.054 \mathrm{PW} \mathrm{Sv}^{-1}(0.045,0.069)$ & $0.15 \mathrm{PW}(-0.32,0.42)$ & $0.93(0.89,0.96)$ & 0.06 PW $(0.04,0.07)$ & 32 \\
\hline $\begin{array}{l}\text { Temperature transport, } \\
T_{\text {ref }}=0^{\circ} \mathrm{C}\end{array}$ & $0.075 \mathrm{PW} \mathrm{Sv}^{-1}(0.067,0.088)$ & $0.93 \mathrm{PW}(0.89,0.96)$ & $0.96(0.94,0.98)$ & 0.06 PW $(0.04,0.07)$ & 32 \\
\hline $\begin{array}{l}\text { Salinity transport, } \\
\quad S_{\text {ref }}=35.156 \mathrm{psu}\end{array}$ & $0.98 \mathrm{~Sv} \mathrm{psu} \mathrm{Sv}{ }^{-1}(0.79,1.29)$ & $1.8 \mathrm{~Sv}$ psu $(-7.7,7.9)$ & $0.83(0.71,0.91)$ & 1.4 Sv psu (1.1 1.8) & 32 \\
\hline $\begin{array}{l}\text { Salinty transport, } \\
\quad S_{\mathrm{ref}}=0 \mathrm{psu}\end{array}$ & 36.00 Sv psu Sv ${ }^{-1}(35.84,36.22)$ & $6.4 \mathrm{~Sv}$ psu $(-0.8,11.3)$ & $\begin{array}{l}0.9999(0.99975 \\
0.99995)\end{array}$ & 1.4 Sv psu $(1.1,1.7)$ & 32 \\
\hline
\end{tabular}

and gives an rms error of $0.06 \mathrm{PW}$ (see Table 1 for values of the best-fit line). If the seasonal cycle were not removed prior to regression, the calibration would be less accurate with an rms error of $0.08 \mathrm{PW}$. The calibration for temperature transport relative to $\theta_{\text {ref }}=0^{\circ} \mathrm{C}$ (not shown, statistics given in Table 1 ) has a slightly higher correlation $(R=0.96)$ and is fully consistent with previous results (Shoosmith et al. 2005). ${ }^{2}$ The seasonal cycle of temperature transport from the CTD/LADCP transects is also consistent with that found by Johns et al. (2011) using Pegasus data. These correspondences with previous results further confirm that the CTD/LADCP dataset is consistent with independent calibration datasets. The CTD/LADCP transects give a consistent though weaker relation between temperature transport and cable voltage than the Pegasus transects.

To obtain a temperature calibration for the cable, we combine our CTD/LADCP-derived calibration with the cable's volume calibration in a two-step procedure (Table 2). The accuracy of the cable temperature transports is calculated assuming independent errors by $\operatorname{sqrt}\left\{[0.06 \mathrm{PW}]^{2}+\left[(1.6 \mathrm{~Sv})(0.054 \mathrm{PW} \mathrm{Sv})^{-1}\right]^{2}\right\}=0.11 \mathrm{PW}$, following the same process and obtaining the same result as Shoosmith et al. (2005) and Johns et al. (2011). Despite the LADCP volume transports being less accurate compared to the cable than the dropsonde transects, we believe that the two-step procedure for temperature

\footnotetext{
${ }^{2}$ The temperature transport regression obtained by Shoosmith et al. (2005) using 58 Pegasus transects and $\theta_{\text {ref }}=0^{\circ} \mathrm{C}$ had a slope of $0.081 \mathrm{PW} \mathrm{Sv}^{-1}$, a $y$ intercept of $-0.041 \mathrm{~Sv}$ (no confidence limits given), a correlation of $R=0.97$, and an rms residual of $0.06 \mathrm{PW}$. Note that Shoosmith et al. (2005) analyzed Pegasus observations with more transects but less accurate temperature measurements than the CTD/LADCP observations.
}

transport gives unbiased results. Though the LADCP velocities may have greater noise than dropsonde measurements, this noise is likely not coherent with any noise in the CTD measurements. To the extent that the CTD/LADCP transects yield an unbiased relation between volume transport and temperature transport, as demonstrated above by comparison to historical results, the two-step method is appropriate. These assumptions are supported in detail by considering patterns of spatial variability (section 5).

\section{c. Salinity transport}

The calibration transects provide a high-precision estimate of the salinity transport that is an important result in itself. The Florida Straits is saltier on average than the basin interior (area-weighted salinity of $35.99 \pm 0.02$ psu, average and $95 \%$ confidence limits from bootstrap analysis), partially due to its shallow depth. The northward salinity transport is even stronger because of surface-intensified currents advecting saline surface water, as shown by the transport-weighted salinity (36.20 $\pm 0.03 \mathrm{psu}$, bootstrap statistics). These averages are not affected by different gridding methods (differences of $0.003 \mathrm{psu}$ ). When calculating salinity transport, we do so relative to the basin-averaged salinity along $26^{\circ} \mathrm{N}\left(S_{\text {ref }}=35.156 \mathrm{psu}\right)$ to simplify interpretation. The CTD/LADCP transects show an average northward transport of $33.0 \mathrm{~Sv}$ psu, a standard deviation of $2.8 \mathrm{~Sv}$ psu, a 90th percentile range of 29.1-37.4 Sv psu (total range of 28.3-38.5 Sv psu), and an error of the mean of $0.5 \mathrm{~Sv}$ psu $(N=32)$.

The calibration of CTD/LADCP salinity transport against LADCP volume transport is performed the same as for temperature transport, except for a lack of seasonal cycle in salinity. Salinity and volume transports from the 
TABLE 2. Summary of best-fit calibrations to obtain temperature and salinity transports based on the cable-derived transport. Fits are of the form $y-\bar{y}=m(x-\bar{x})$, where $x$ is cable-derived volume transport, $y$ is the variable in the first column, $\bar{x}=31.7 \mathrm{~Sv}, \bar{y}$ is the average of the $32 \mathrm{CTD} / \mathrm{LADCP}$ transects, and $m$ is the slope. The rms error and $R$ are calculated by combining errors from the operational cable calibration and from the fits shown in Table 1, assuming independence, and in relation to the total standard deviation (std dev) of $y$ (see text for details).

\begin{tabular}{|c|c|c|c|c|c|}
\hline & $m$ & $\bar{y}$ & Std dev $(y)$ & rms error & $R$ \\
\hline Temperature transport, $T_{\text {ref }}=5.33^{\circ} \mathrm{C}$ & $0.055 \mathrm{PW} \mathrm{Sv}^{-1}$ & $1.88 \mathrm{PW}$ & $0.17 \mathrm{PW}$ & $0.11 \mathrm{PW}$ & 0.73 \\
\hline Temperature transport, $T_{\text {ref }}=0^{\circ} \mathrm{C}$ & $0.075 \mathrm{PW} \mathrm{Sv}^{-1}$ & $2.57 \mathrm{PW}$ & $0.22 \mathrm{PW}$ & $0.11 \mathrm{PW}$ & 0.85 \\
\hline Salinity transport, $S_{\text {ref }}=35.156 \mathrm{psu}$ & $0.98 \mathrm{~Sv}_{\mathrm{psu} \mathrm{Sv}}^{-1}$ & $32.8 \mathrm{~Sv}$ psu & $2.7 \mathrm{~Sv}$ psu & $2.2 \mathrm{~Sv}$ psu & 0.62 \\
\hline Salinity transport, $S_{\mathrm{ref}}=0 \mathrm{psu}$ & $36.01 \mathrm{~Sv} \mathrm{psu} \mathrm{Sv}^{-1}$ & 1141.4 Sv psu Sv ${ }^{-1}$ & $98.3 \mathrm{~Sv}$ psu & $2.1 \mathrm{~Sv}$ psu & 0.9998 \\
\hline
\end{tabular}

CTD/LADCP transects are well correlated (Fig. 4), though the correlation $(R=0.84)$ is slightly lower than for temperature transport (see Table 1 for fitting coefficients). The rms residual is $1.4 \mathrm{~Sv}$ psu, smaller than the transect standard deviation of $2.7 \mathrm{~Sv}$ psu. In comparison, regressing salinity transport directly against cable voltage yields a weaker correlation with principal component regression $(R=0.33)$ or with least squares fitting $(R=0.55)$.

Proceeding as in the previous subsection, we calculate the salinity transport from the cable transport (see Table 2 for statistics). Assuming errors are uncorrelated yields an error estimate of $\operatorname{sqrt}\left\{[1.4 \mathrm{~Sv} \mathrm{psu}]^{2}+\right.$ $\left.\left[(1.6 \mathrm{~Sv})\left(0.98 \mathrm{~Sv}_{\mathrm{psu} \mathrm{Sv}}{ }^{-1}\right)\right]^{2}\right\}=2.2 \mathrm{~Sv}$ psu. This two-step approach is supported by the close correspondence of our CTD/LADCP temperature calibration with previous estimates, and is discussed further in section 5 . The calibration accuracy is small enough to resolve typical fluctuations in salinity transport: the rms error of the calibration (2.2 Sv psu) is smaller than the standard deviation of the transects $(2.7 \mathrm{~Sv}$ psu), and is much smaller than the $90 \%$ range of the transects (28-38 Sv psu).

For basinwide calculations of freshwater flux that require mass conservation (Lavín et al. 2003; E. McDonagh et al. 2013, unpublished manuscript), the reference salinity is arbitrary and does not affect the results. For use in such studies that enforce mass conservation, we show results using $S_{\text {ref }}=0$ psu that yield a highly linear fit $(R=0.9999$, Table 1$)$. Such zero-referenced salinity transports are not physically meaningful by themselves, however, because they are almost entirely compensated by southward transport in the basin interior. In addition, their large magnitude obscures the small fluctuations that determine the accuracy of salinity calibrations.

The salinity calibration is less accurate than the temperature calibration, which implies that salinity fluctuations are less coherent with velocity fluctuations than are temperature fluctuations. This is investigated in section 5. Summaries of best fits for temperature and salinity transports are listed in Table 2 based on the CTD/ LADCP dataset.
The salinity calibration applied to the cable voltages (Fig. 5) shows that large transport fluctuations dominate the time series. The cable time series has a larger standard deviation (3.3 Sv psu) than the calibration transects, but it has a similar range. Thus, the cable-derived salinity transport is accurate enough to confidently resolve typical and large fluctuations in salinity transport.

\section{Vertical profiles of salinity transport}

Vertical profiles of salinity transport are necessary for interpreting basinwide freshwater flux. We derive them here, and note that similar methods can be used to reconstruct transports in temperature, salinity, or density classes.

As we are limited to working from a single continuous measured variable, the cable measurement, we must rely on defining a vertical profile against which to multiply the cable transport. We consider two methods: 1) using the first empirical orthogonal function (EOF) from nondemeaned vertical profiles (gray line in Fig. 6a) and 2) using a linear fit at each depth level (black line in

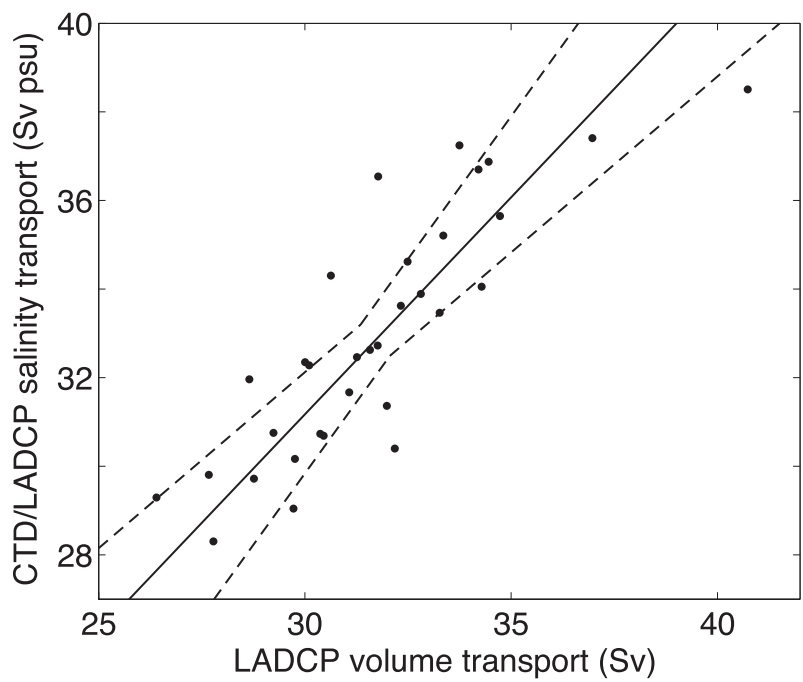

FIG. 4. As in Fig. 3, but between CTD/LADCP salinity transport relative to $S_{\text {ref }}=35.156 \mathrm{psu}$ and LADCP volume transport (dots). 


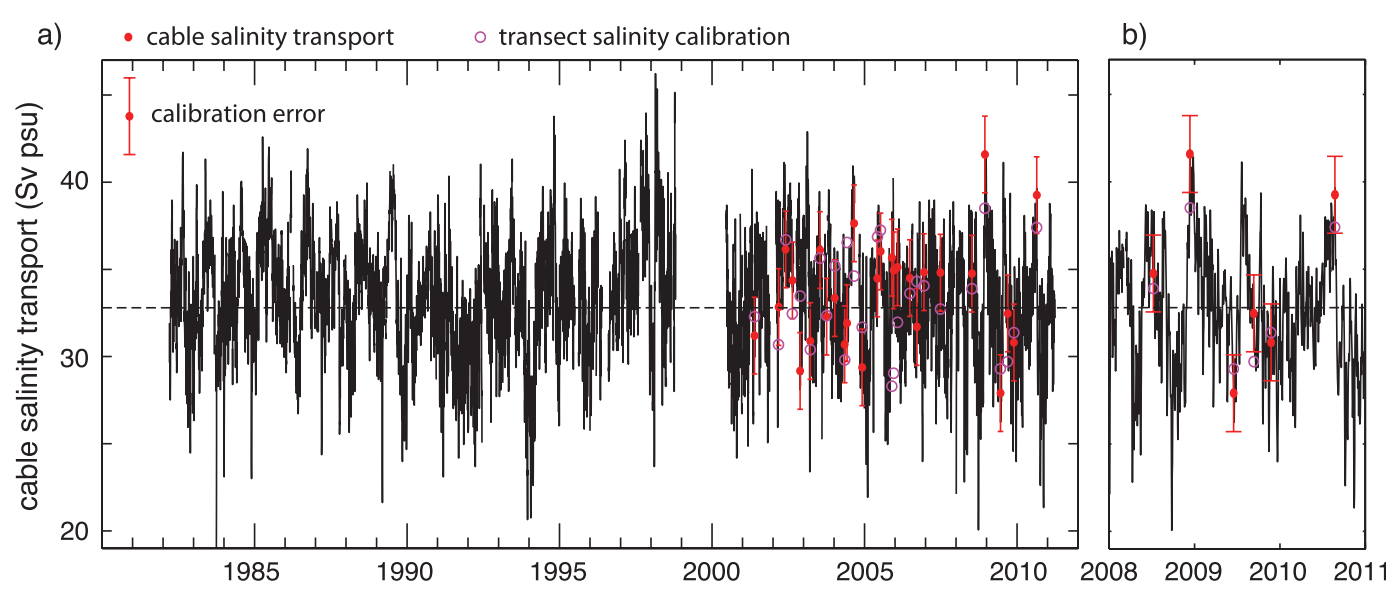

FIG. 5. Salinity transport (relative to $S_{\text {ref }}=35.156 \mathrm{psu}$ ) from the cable (black line) and from the CTD/LADCP transects (magenta circles). Cable-derived transport at the same date as the transects (red dots) are highlighted, with uniform error bars showing the daily accuracy of the cable (red bars, $\pm 2.2 \mathrm{~Sv}$ psu). Average value ( $33.0 \mathrm{~Sv} \mathrm{psu}$ ) is shown by a dashed line. (a) Full time series from the cable. (b) Three years are shown in expanded view to show the comparison between the cable estimates and the calibration transects.

Fig. 6a). The first method, following Cunningham et al. (2007) and Johns et al. (2011), scales the average profile by a constant to obtain the reconstructed profile. In contrast, the second method utilizes a profile of fluctuations in addition to the average profile. This is useful if the standard deviation is not related to the average by a uniform factor at all depths. The EOF profile from method 1 (Fig. 6a) is effectively the average vertical profile, but it is does not reflect the increased variability above $150 \mathrm{~m}$ seen in the profile from method 2 .

a)

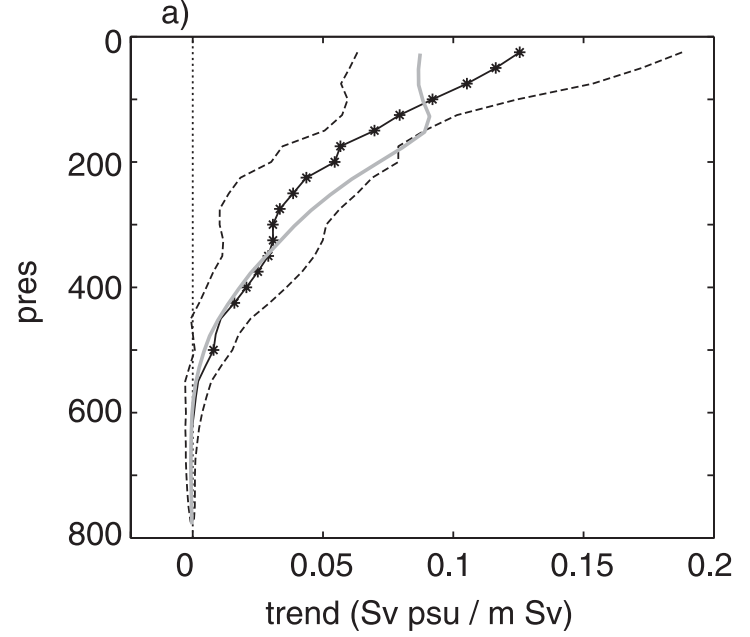

The average profile of salinity transport per unit depth (Fig. 6b) is surface intensified, but is nearly uniform above $150 \mathrm{~m}$. Fluctuations are largest at the surface and decay in magnitude with depth. Below $600 \mathrm{~m}$ average salinity transport is negative because the salinity is less than the reference salinity. The two methods yield rms errors less than the standard deviation from calibration cruises ( $0.5 \mathrm{~Sv}$ psu at the surface), but the second method has a smaller error in the upper $150 \mathrm{~m}$. Because the signal in the upper $200 \mathrm{~m}$ constitutes most of the

FIG. 6. Vertical profiles of salinity transport. (a) Profile of the slope of unit salinity transport against total salinity transport (black solid) with confidence limits (black dashed) and depths of statistically nonzero slopes (shown as *), and normalized first EOF of nondemeaned unit salinity transport (thick gray). Both profiles are normalized to have the same integrated salinity transport. (b) Salinity transport per unit depth, average (thick black), and standard deviation (black dashed, shown twice: once about the mean and once about 0 ). Residuals of rms are shown for reconstructions from a point-slope fit (thin black) and from the first nondemeaned EOF (thick gray). 
northward salinity flux relative to profiles from the basin interior (Lavín et al. 2003), the second method is recommended. The second method is slightly more accurate using a uniform reference salinity as done here, but it would likely be even more accurate when profiles from the interior are used for reference.

Error as a function of depth is a combination of the rms residuals calculated against the CTD/LADCP calibration profiles and of errors from the cable calibration, the same as for errors in cable-derived temperature and salinity transports. For simplicity, we choose to spread the previously identified error of $2.7 \mathrm{~Sv}$ psu in the cable salinity transport throughout the water column with the same vertical structure used to recreate the profiles, giving a surface error of $0.3 \mathrm{~Sv}$ psu that decreases with depth. This choice reflects the profile of standard deviation, which is largest at the surface $(0.6 \mathrm{~Sv} \mathrm{psu})$ and decreases with depth. Assuming independence, the total error of the cable-derived salinity transport profile is the same as the standard deviation in the upper $150 \mathrm{~m}$ ( $0.6 \mathrm{~Sv}$ psu), but is $10 \%$ larger below $150 \mathrm{~m}$.

\section{EOF modes in the Florida Straits}

To understand why temperature transport is recovered with better accuracy than salinity transport, we consider the spatial average and variability of velocity, temperature, and salinity through an EOF analysis (Fig. 7). We subtract the seasonal pattern of near-surface temperature as previously described prior to calculating EOFs.

For velocity, the first two EOFs explain 30\% and $21 \%$ of the total variance but are not clearly separated from higher-mode EOFs. For temperature and salinity, the first EOFs are strong modes of variability (explaining $57 \%$ of the variance for temperature, $45 \%$ for salinity), while the second EOFs (12\% variance for temperature, $13 \%$ for salinity) are not distinct from higher EOFs.

Both velocity and temperature are surface intensified in their average fields. Surface-intensified velocity EOFs preferentially advect warm water, which translates directly into increased temperature transport. In the same fashion, seasonal heating (though removed prior to EOF analysis) occurs in regions of fast average velocity and large velocity fluctuations. These empirical spatial and seasonal correlations between velocity and temperature increase the accuracy of the cable-derived temperature transport (discussed in section 3b).

In contrast, the average salinity field (Fig. 7d) shows a maximum at middepths (100-200 m) on the eastern side of the straits and a minimum near the bottom along the western slope. It is waters of intermediate salinity that correspond either to regions of large average velocity or to regions of strong velocity fluctuations. Accordingly, there is a weaker correlation between salinity transports and volume transports. In general, larger volume transports simply transport more salt compared to the midocean because of the higher average salinity in the Florida Straits.

The first EOFs of salinity and temperature are spatially very similar and temporally highly negatively correlated ( $R=-0.96)$, and so it is worth considering whether they are linked through the geostrophic relationship with velocity. Joint EOFs of temperatureinduced density fluctuations, salinity-induced density fluctuations, and velocity fluctuations (results not shown) confirm that the first three modes of variability are consistent with changes in geostrophic velocity. The density influence of salinity is always opposite that of temperature. The role of temperature is large near the surface, where salinity is mostly uniform, whereas temperature and salinity contribute equally in deeper waters, which are less strongly stratified. The first joint EOF explains $30 \%$ of the variance in the upper $300 \mathrm{~m}$ with intensification on the western side, while the second joint EOF explains 19\% of the variance and describes velocity localized near the sloping western boundary. Both EOFs contain temperature and salinity fluctuations that are maximum along the sloping western boundary. The second EOF has greater overlap between velocity and temperature/salinity than the first EOF. The dynamical reasons for these patterns, whether they are caused by meanders, winds, or shelf waves, are not investigated here and the reader is referred to Johns and Schott (1987).

The extent of covariability between velocity and salinity is also relevant to whether calibration errors in salinity transport are independent of errors in volume transport. The joint EOFs of velocity, temperature, and salinity discussed above provide EOFs that are entirely coherent between these quantities. Although the first joint EOF leads to a significant change in volume transport (1.3 Sv for one standard deviation), the change in salinity transport due to the joint EOFs of salinity and velocity is 15 times smaller than that due to the salinity EOF and the average velocity field. The same is true for higher EOFs and for temperature transport: the average velocity field is at least an order of magnitude more important for salinity/temperature transport than the EOF velocity field. When compared against the corresponding individual EOFs shown in Fig. 7, the joint EOFs have a roughly similar spatial structure but lack a 1-to-1 correspondence in the temporal amplitude. These results support treating calibration errors between the cable volume transport and the CTD/LADCP-derived salinity (or temperature) transports as independent. Additionally, these results suggest that any noise in the LADCP 

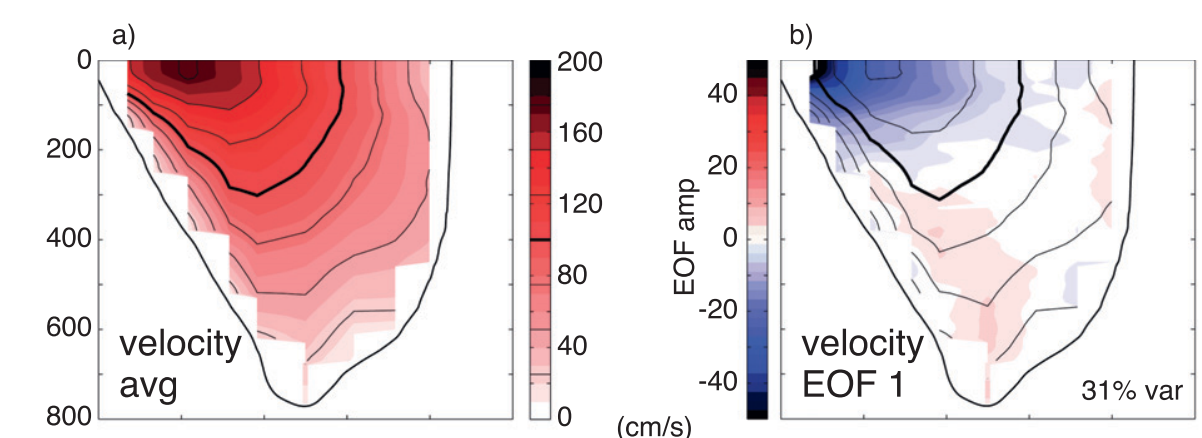

c)

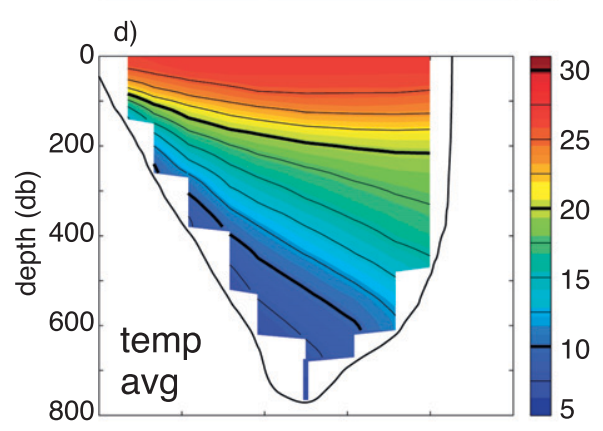

$(\mathrm{cm} / \mathrm{s})$
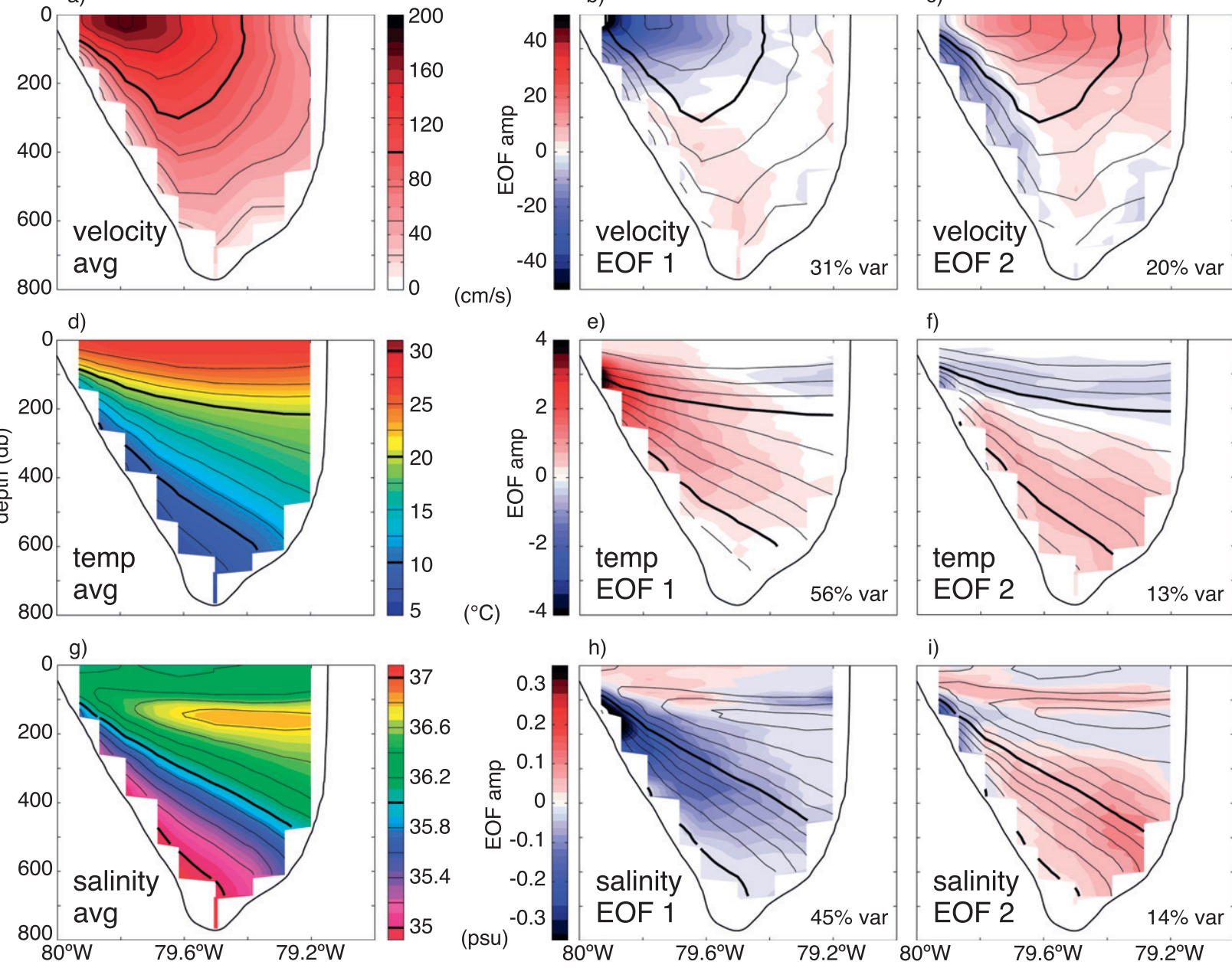

$\left({ }^{\circ} \mathrm{C}\right)$
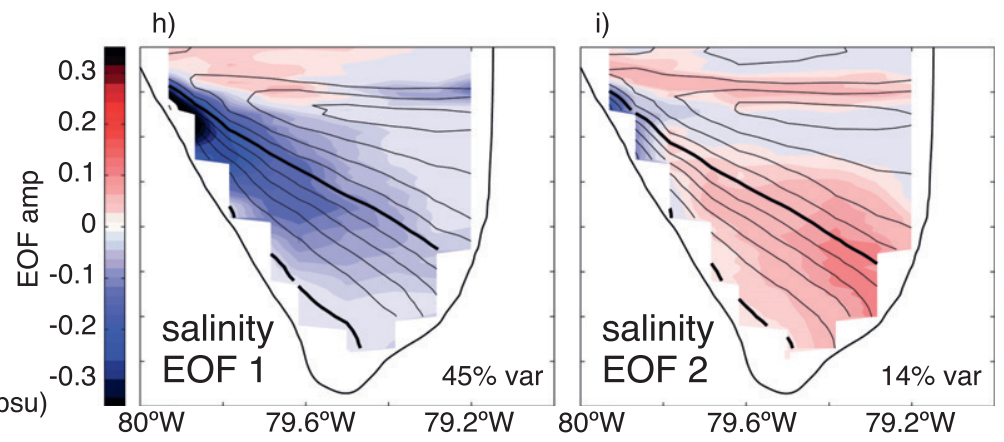

FIG. 7. EOF analysis of velocity, temperature, and salinity. Each row shows the time-averaged structure and the first and second EOFs, for (a)-(c) velocity, (d)-(f) potential temperature, and (g)-(i) salinity. Time-average subplots show the same quantities in color and with the black contours. EOF subplots show the dimensional amplitude in color (EOFs amplitude multiplied by the eigenvalue), with the corresponding absolute field (time-averaged field plus the EOF) shown by black contours. Isotachs are shown every $25 \mathrm{~cm} \mathrm{~s}{ }^{-1}$ with thick lines at 100 and $200 \mathrm{~cm} \mathrm{~s}^{-1}$; isotherms are shown every $2.5^{\circ} \mathrm{C}$ with thick lines at $10^{\circ}$ and $20^{\circ} \mathrm{C}$; and isohalines are shown every 0.2 psu with thick lines at 35 and 36 psu.

data is not likely to introduce biases into the two-step procedure adopted to define salinity or temperature calibrations.

\section{Discussion and conclusions}

The CTD/LADCP transects provide salinity transport of the Florida Current from numerous (32) direct estimates during all seasons: the average value (33.0 Sv psu) is calculated to an accuracy ( $0.5 \mathrm{~Sv}$ psu, standard error of the mean) 5 times better than previously calculated from infrequent hydrographic transects (accurate within 2.4 Sv psu; Lavín et al. 2003). The calibrated salinity transport derived from the submarine cable has the same accuracy (2.2 Sv psu for each daily estimate) as that obtained from previous hydrographic transects. The calibration transects and time series show large fluctuations, $\pm 5 \mathrm{~Sv}$ psu, from the mean that are well resolved by the cable calibration.

Cable calibrations ultimately work because the voltage induced in the submarine cable is correlated with transports of volume, temperature, or salinity. For temperature and salinity transports in particular, this methodological approach is analogous to the gravest empirical mode method for interpreting inverted echo sounders (Meinen and Watts 1998), in that it takes advantage of intrinsic modes of oceanic variability to interpret an integral measure (such as sound travel time or cable voltage; Luther and Chave 1993). In the Florida Straits, we find that the cable is a good predictor for temperature 
and salinity transports for two reasons. First, the geometry of the straits and underlying sediments cause the voltage to be an unambiguous measure of conductivityweighted volume transport (Spain and Sanford 1987; Larsen 1992). Second, relatively high averages in conductivity, temperature, and salinity provide empirical linear relationships between conductivity-weighted transport and transports of volume, temperature, and salinity. The large average value of electrical conductivity causes conductivity and volume transports to be very tightly linked, which explains the accurate calibration of cable voltage with volume transport. Because the Florida Straits is warmer and saltier than the basin interior, a large fraction of temperature and salinity transports is due to the velocity field advecting the average temperature and salinity fields.

Aside from the basin-averaged reference temperature and salinity being less than averages in the Florida Straits, there is little spatial covariability associated with net transports between velocity and temperature or salinity. This lack of coherence supports our earlier assumption that errors in volume transport and in temperature or salinity transport can be treated as independent when calculating calibration accuracies. Overlap between temperature and salinity stratification and the average velocity field explain the remaining differences between the accuracies of temperature and salinity calibrations. The better accuracy for temperature arises because of the more pronounced near-surface stratification of temperature compared to salinity stratification, and additionally because near-surface seasonality in temperature occurs where velocities are fastest.

A more critical test of the covariability of spatial patterns would be to calculate temperature and salinity transports relative to the average temperature or salinity in the Florida Straits. Transports calculated using these larger reference values $\left(19.78^{\circ} \mathrm{C}\right.$ and $\left.36.20 \mathrm{psu}\right)$ are completely uncorrelated with volume transport (results not shown). This result indicates that fluctuations in the Florida Straits do not have a dominant mode of covariability between velocity, temperature, or salinity, and that the mean fields contribute significantly to fluctuations of northward transport. Fortunately, the Florida Current advects both heat and salt northward, and so transports suitable for basinwide flux calculations can be recovered relative to the basin interior.

The CTD/LADCP data presented here can be used to directly test the empirical relationship between the cable voltage and transports of volume, temperature, and salinity. Though cable voltage is best correlated with conductivity-weighted transport, as expected, the correlation is virtually identical to those with conductivity or volume transport. The correlation is slightly lower for temperature transport, and lower still for salinity transport, but all correlations are well within the large statistical uncertainty that is characteristic of our calibration dataset. Within the CTD/LADCP measurements, volume transport is highly correlated with conductivity transport or with conductivity-weighted volume transport ( $R=0.99$ for both), highlighting how variability in ocean electrical conductivity is minor compared to its average (47 $\pm 7 \mathrm{~S} \mathrm{~m}^{-1}$, spatial average \pm standard deviation in the Florida Straits). The weaker correlation between volume transport and temperature or salinity transport partially reflects the increased importance of covariability when using references closer to the average. Although the CTD/LADCP transects give results consistent with the theory, external noise and internal oceanic variability dominate the accuracy of calibrating the cable voltage.

In terms of what transport the cable responds to, our results are factually consistent with those of Shoosmith et al. (2005). Despite having more transects, their correlations between cable voltage and volume, temperature, or conductivity transport are not statistically distinguishable from each other. Their reliance on indirect conductivity is likely responsible for conductivity transport being slightly less correlated with the cable than volume or temperature transport. Given these qualifications, we find their results consistent with ours and with the theory.

Extending the concept that cable calibrations rely on intrinsic variability, additional independent measurements may provide further information that could improve the accuracy of the cable calibration through a multivariate regression. An attempt to do so was made by incorporating dynamic height as a proxy for sea surface height ( $\mathrm{SSH})$, from which distinct cross-strait EOFs were included in a multivariate regression. Although multivariate regressions slightly improved the reconstruction of temperature transport, they did not significantly improve reconstructions of volume or salinity transport. In practice, the suitability of near-shore satellite altimetry is questionable, because of both signal degradation close to coastlines [perhaps recoverable by coastal SSH products such as Prototype Innovant de Système de Traitement pour l'Altimétrie Côtière (PISTACH); Mercier et al. 2010] and the mismatch of temporal and spatial resolution between altimetry and the cable measurements. Another satellite product, sea surface temperature, would respond to the seasonal cycle of near-surface temperature and so is expected to improve estimates of temperature transport but not volume or salinity transport.

For calibrating submarine cables in other locations, the geometry and nature of the flow may be more amenable to multivariate approaches. For instance, one 
of the earliest attempts to measure the Florida Current used a cable from the Florida Keys to Havana, Cuba (Wertheim 1954), where the current has room to meander from side to side. Aside from historical limitations present at the time-no independent calibration data, inexact interpretation of the cable voltages, and no recognition that quick changes in volume transport are possible-voltages at this location could be more clearly interpreted if the horizontal location of the current (from, e.g., altimetry) is included in the analysis (T. B. Sanford 2005, personal communication).

When considered in terms of the basinwide salt or freshwater flux, the large and variable transport in the Florida Straits is a large component of the basinwide signal (E. McDonagh et al. 2013, unpublished manuscript). Even though salinity is maximum at middepths, vertical profiles of salinity transport are large and uniform in magnitude in the upper $150 \mathrm{~m}$ because of surface-intensified velocity. The deep part of the straits contributes little to the salinity transport relative to the basin average because it is close to the reference salinity. Waters below $600 \mathrm{~m}$ are fresher than the reference salinity and thus contribute negative northward salinity transport. Though the basin-averaged salinity at $26^{\circ} \mathrm{N}$ is fresher than the average in the Florida Straits because of relatively freshwater below $1000 \mathrm{~m}$, on constant depth surfaces the Florida Straits are fresher than the interior. In particular, the strait contains freshwater on the eastern side and in the entire surface above $100 \mathrm{~m}$ that is ultimately of South Atlantic origin (Schmitz and Richardson 1991). This results in the northward salinity flux being confined to the upper $200 \mathrm{~m}$ relative to the basin interior at the same depths, with a negative contribution from deeper depths (Lavín et al. 2003). In contrast, salinity transport in the basin interior has low variability in the deep layers that compensate for the northward volume flux in the Florida Current. With the Florida Straits calibrated for salinity transport, we can now investigate the processes responsible for maintaining the salt and freshwater balance at $26^{\circ} \mathrm{N}$ in the subtropical Atlantic.

Acknowledgments. The cable data, calibration transects, and C. M. are supported through the Western Boundary Time Series project, which is funded through the NOAA Climate Observations Division. Z. B. S. was supported by an Abrupt Climate Change Research fellowship from the Comer Science and Education Foundation and by the Max Planck Society for the Advancement of Science. The Florida Current data are made freely available by the AOML Physical Oceanography Division (at http://www.aoml.gov/phod/floridacurrent) through funding from NOAA. The authors thank
E. McDonagh and the anonymous reviewers for their helpful discussions and suggestions.

\section{REFERENCES}

Baringer, M. O., and J. C. Larsen, 2001: Sixteen years of Florida Current transport at $27^{\circ}$ N. Geophys. Res. Lett., 28, 3179-3182.

Beal, L. M., W. P. M. De Ruijter, A. Biastoch, R. Zahn, and SCOR/ WCRP/IAPSO Working Group 136, 2011: On the role of the Agulhas system in ocean circulation and climate. Nature, $\mathbf{4 7 2}$, 429-436, doi:10.1038/nature09983.

Belkin, I. M., S. Levitus, J. Antonov, and S.-A. Malmberg, 1998: "Great Salinity Anomalies" in the North Atlantic. Prog. Oceanogr., 41, 1-68.

Biastoch, A., C. W. Böning, F. U. Schwarzkopf, and J. R. E. Lutjeharms, 2009: Increase in Agulhas leakage due to poleward shift of Southern Hemisphere westerlies. Nature, 462 , 495-498.

Cimatoribus, A. A., S. S. Drijfhout, M. den Toom, and H. A. Dijkstra, 2012: Sensitivity of the Atlantic meridional overturning circulation to South Atlantic freshwater anomalies. Climate Dyn., 39, 2291-2306.

Cook, R. D., 1979: Influential observations in linear regression. J. Amer. Stat. Assoc., 74, 169-174.

Cunningham, S. A., and Coauthors, 2007: Temporal variability of the Atlantic meridional overturning circulation at $26.5^{\circ} \mathrm{N}$. Science, 317, 935-938, doi:10.1126/science.1141304.

Curry, B., C. M. Lee, and B. Petrie, 2011: Volume, freshwater, and heat fluxes through Davis Strait, 2004-05. J. Phys. Oceanogr., 41, 429-436.

Curry, R. G., M. S. McCartney, and T. M. Joyce, 1998: Oceanic transport of subpolar climate signals to mid-depth subtropical waters. Nature, 391, 575-577.

Emery, W. J., and R. E. Thomson, 1998: Data Analysis Methods in Physical Oceanography. Pergamon, $634 \mathrm{pp}$.

Hall, M. M., and H. L. Bryden, 1982: Direct estimates and mechanisms of ocean heat transport. Deep-Sea Res., 29A, 339-359.

Johns, W. E., and F. A. Schott, 1987: Meandering and transport variations of the Florida Current. J. Phys. Oceanogr., 17,11281147.

— , and Coauthors, 2011: Continuous, array-based estimates of Atlantic Ocean heat transport at $26.5^{\circ}$ N. J. Climate, 24, 24292449.

Larsen, J. C., 1992: Transport and heat flux of the Florida Current at $27^{\circ} \mathrm{N}$ derived from cross-stream voltages and profiling data: theory and observations. Philos. Trans. Roy. Soc. London, 338A, 169-236.

—_ and T. B. Sanford, 1985: Florida Current volume transport from voltage measurements. Science, 227, 302-304.

Lavín, A. M., H. L. Bryden, and G. Parrilla, 2003: Mechanisms of heat, freshwater, oxygen and nutrient transports and budgets at $24.5^{\circ}$ in the subtropical North Atlantic. Deep-Sea Res. I, 50, 1099-1128.

Luther, D. S., and A. D. Chave, 1993: Observing "integrating" variables in the ocean. Statistical Methods in Physical Oceanography: Proc. 'Aha Huliko'a Hawaiian Winter Workshop, Honolulu, HI, University of Hawaii at Manoa, 103-129.

Mayer, D. A., K. D. Leaman, and T. N. Lee, 1984: Tidal motions in the Florida Current. J. Phys. Oceanogr., 14, 1551-1559.

Meinen, C. S., and D. R. Watts, 1998: Calibrating inverted echo sounders equipped with pressure sensors. J. Atmos. Oceanic Technol., 15, 1339-1345. 
_- M. O. Baringer, and R. F. Garcia, 2010: Florida Current transport variability: An analysis of annual and longerperiod signals. Deep-Sea Res. I, 57, 835-846, doi:10.1016/ j.dsr.2010.04.001.

Mercier, F., V. Rosmorduc, L. Carrer, and P. Thibaut, 2010: Coastal and hydrology altimetry product (PISTACH) handbook. Centre National d'Études Spatiales Tech. Rep. CLSDOS-NT-10-246, 58 pp.

Molinari, R. L., W. D. Wilson, and K. D. Leaman, 1985: Volume and heat transports of the Florida Current: April 1982 through August 1983. Science, 227, 295-297.

Sanford, T. B., 1971: Motionally induced electric and magnetic fields in the sea. J. Geophys. Res., 76 (15), 3476-3492.

Schmitz, W. J., Jr., and P. L. Richardson, 1991: On the sources of the Florida Current. Deep-Sea Res., 38A (Suppl.), S379-S409.

Shoosmith, D. R., M. O. Baringer, and W. E. Johns, 2005: A continuous record of Florida Current temperature transport at $27^{\circ}$ N. Geophys. Res. Lett., 32, L23603, doi:10.1029/ 2005 GL024075.
Spain, P., and T. B. Sanford, 1987: Accurately monitoring the Florida Current with motionally induced voltages. J. Mar. Res., 15, 599-608.

— D. Dorson, and T. H. Rossby, 1981: PEGASUS: A simple, acoustically tracked, velocity profiler. Deep-Sea Res., 28A, 1553-1567.

Szuts, Z. B., 2012: Using motionally-induced electric fields to indirectly measure ocean velocity: Instrumental and theoretical developments. Prog. Oceanogr., 96, 108-127, doi:10.1016/ j.pocean.2011.11.014.

_, J. R. Blundell, M. P. Chidichimo, and J. Marotzke, 2011: A vertical-mode decomposition to investigate low-frequency internal motion across the Atlantic at $26^{\circ} \mathrm{N}$. Ocean Sci. Discuss., 8, 2047-2100, doi:10.5194/osd-8-2047-2011.

Wertheim, G. K., 1954: Studies of the electric potential between Key West, Florida and Havana, Cuba. Eos, Trans. Amer. Geophys. Union, 35, 872-882.

Wunsch, C., 2006: Discrete Inverse and State Estimation Problems. Cambridge University Press, 371 pp. 
Copyright of Journal of Atmospheric \& Oceanic Technology is the property of American Meteorological Society and its content may not be copied or emailed to multiple sites or posted to a listserv without the copyright holder's express written permission. However, users may print, download, or email articles for individual use. 